\title{
Centros escolares e supervisão colaborativa: perspetivas quanto ao contributo para o desenvolvimento profissional e a melhoria das práticas pedagógicas - um estudo em \\ curso
}

School centers and collaborative supervision: perspectives on their contribution for
professional development and the improvement of pedagogical practices - an ongoing

study

Helena Maria Cerqueira Gonçalves Miranda Licenciada em Comunicação educacional e Gestão da informação; Mestranda em Supervisão Pedagógica pela Universidade Aberta, Portugal; Investigadora do LE@D, Universidade Aberta, Lisboa, Portugal. helenamir@gmail.com

\begin{abstract}
Filipa Seabra
Doutorada em Ciências da Educação, na especialidade de Desenvolvimento Curricular; Professora Auxiliar da Universidade Aberta, Porto, Portugal, onde é coordenadora do Mestrado em Supervisão Pedagógica; Investigadora do LE@D, Universidade Aberta, Lisboa, Portugal; do CIEd, Universidade do Minho, Braga, Portugal, e do CIPEM/INET-MD, Porto, Portugal. filipa.seabra@uab.pt
\end{abstract}

\begin{abstract}
Resumo: Este artigo avança dados preliminares de um estudo em curso sobre condutas colaborativas como forma de supervisão entre pares direcionada para a melhoria das práticas pedagógicas. A questão enfatizada é: até que ponto e de que forma a nova realidade dos centros escolares, proporcionando a agregação de docentes, terá repercussões nas suas práticas colaborativas e de supervisão. Os dados foram recolhidos em entrevistas de grupo focal a docentes de educação pré-escolar e $1^{\circ}$ ciclo do ensino básico que transitaram de escolas isoladas para centros escolares de um dado agrupamento de escolas. Após breve explanação dos conceitos envolvidos e da metodologia do estudo, discutem-se alguns dados relativos às tendências de resposta face aos tópicos: mudanças nas práticas docentes; perspetivas sobre supervisão colaborativa; e individualismo vs. colaboração. Os participantes tendem a reconhecer a influência da mudança para centros escolares nas práticas colaborativas, mas não tanto na melhoria das suas práticas docentes e não se identificam com a expressão supervisão colaborativa, sugerindo outra terminologia.
\end{abstract}

Palavras-Chave: Supervisão Educacional. Supervisão Colaborativa. Desenvolvimento Profissional. Escolas Aprendentes. Centros Escolares.

Abstract: This article presents preliminary data from an ongoing study, focusing on the collaborative practices as a form of peer supervision aimed at the improvement of pedagogical practices. The point that is emphasized is: to what extent and how may the new reality of school centers, by providing teacher aggregation, have repercussions on their collaborative and supervisory practices. Data were gathered through focus group interviews with the collaboration of preschool and 1st cycle of basic education teachers who have made a transition from isolated schools to school centers, within a certain cluster of schools. After a brief theoretical explanation of the concepts involved the methodology of the study is outlined and some data discussed. In particular, answers focusing on three topics concerning the changes to teachers' practices, perspectives on collaborative supervision and individualism vs. collaboration are presented. Participants tend to acknowledge the influence of the transition to school centers on collaborative practices, but not so much in regards to their teaching practices or as a recognition of a form of supervision.

Keywords: Educational supervision. Collaborative supervision. Professional development. Learning schools. School centers. 


\section{Introdução}

Num cenário educativo em reconstrução - seja pelas diretivas nacionais do contexto português, que incentivam e promovem novas atitudes perante a educação e perante a supervisão pedagógica, seja pelas iniciativas individuais das escolas e dos profissionais da educação que sentem a necessidade de investir na qualidade educativa e revalorizam as culturas de interação entre os docentes - o reconhecimento do papel dos pares e, particularmente, das suas interações, na melhoria do desempenho docente é uma questão emergente, como comprovam diversos estudos recentes, entre os quais Pedras e Seabra (2016), ou Marcos, Machado e Abelha (2014). Ao nível das diretivas nacionais, é exemplo a Avaliação Externa das Escolas, desde o $1^{\circ}$ ciclo avaliativo. O respetivo referencial aponta como um dos seus objetivos "fomentar nas escolas uma interpelação sobre a qualidade das suas práticas e dos seus resultados” (IGE, 2011, p. 7). Esta orientação é incrementada no terceiro ciclo avaliativo (IGE: 2019), o qual enfatiza, no seu quadro de referência, a "articulação curricular vertical e horizontal" (p. 4) e os "mecanismos de regulação por pares e trabalho colaborativo" (p. 6).

Este papel dos docentes na melhoria da sua própria profissionalidade é referido, entre outros, por Hargreaves (2014), numa das suas palestras em vídeo, no Boston College. A dado trecho (minuto 7.17'), refere que os professores em conjunto serão melhores do que são sozinhos e, assim, podem desenvolver as suas competências (tradução nossa).

Também em Portugal tem havido uma ênfase crescente na colaboração entre docentes: que "deve proporcionar a cada um novas relações e contextos de desenvolvimento e de aprendizagem com os outros, criando idealmente a existência de comunidades" e assim, ser orientada para o desenvolvimento e a qualidade educativa (ALARCÃO; CANHA, 2013, p. 81). Neste quadro, Prates, Aranha e Loureiro (2010), chamam a atenção para a função motivadora, esclarecedora e dinamizadora de práticas de supervisão formativa e colaborativa, assinalando que a supervisão não se restringe necessariamente à regulação de processos de ensino e aprendizagem e pode alargar-se à escola como organização reflexiva - perspetiva que Gaspar, Seabra e Neves (2012, p. 31) explicitam como uma "supervisão de matriz essencialmente reflexiva, horizontal, colaborativa ou de auto-supervisão, inscrita numa tendência de desenvolvimento profissional e colaboração".

Tal entendimento dos fatores de melhoria do desempenho docente e da qualidade da escola articula-se com as questões de supervisão, o que nos leva a questionar: qual o objetivo da 
supervisão senão o de potenciar uma reflexão, uma reavaliação e uma melhoria da profissionalidade?

Este papel mais recente da supervisão, de pendor colaborativo, enquanto prática transformadora, sustenta-se em diversos procedimentos e estratégias de ação, o enfoque situa-se, visivelmente, nos docentes. $\mathrm{O}$ trabalho colaborativo emerge como prática a valorizar, segundo, entre outros, Prates, Aranha e Loureiro (2010); Gaspar, Seabra e Neves, (2012); Alarcão e Canha (2013); Hargreaves (2014); Marcos, Machado e Abelha, (2014); Pedras e Seabra, (2016); Gaspar et al (2019). É nesta linha de pensamento que se inscreve o estudo em curso, direcionado para a caraterização de práticas colaborativas de supervisão entre pares, eventualmente relacionadas com a agregação de escolas/docentes em centros escolares e cuja questão de partida é: Que repercussões da sua transição de escolas isoladas para centros escolares são identificadas pelos professores e educadoras de infância, no que concerne aos processos de supervisão colaborativa, de desenvolvimento profissional e melhoria das práticas pedagógicas?

O estudo tem como objetivos centrais:

1) Conhecer as conceções e sentimentos de docentes de educação pré-escolar e $1^{\circ}$ ciclo do ensino básico que lecionam em centros escolares de um agrupamento acerca da supervisão colaborativa e das suas eventuais mais-valias para o desenvolvimento profissional e a melhoria das práticas pedagógicas;

2) Caracterizar as suas vivências quanto à transição de escolas isoladas para centros escolares, no que concerne a práticas consentâneas com a supervisão colaborativa que possa eventualmente existir no centro escolar;

3) Perceber de que forma relacionam a sua transição de escolas isoladas para centros escolares com o seu desenvolvimento profissional e a melhoria das práticas curriculares e pedagógicas.

Assim, o ponto seguinte aflora os conceitos envolvidos para, posteriormente, se apresentar o estudo, quanto à metodologia usada e a alguns resultados que se vêm evidenciando.

\section{Os centros escolares: de uma colegialidade forçada a alfobre de práticas de colaboração}

Em Portugal, os centros escolares são estabelecimentos de maior, ou de menor dimensão, que englobam vários grupos-turma de educação de infância (3 a 5 anos) e de $1^{\circ}$ ciclo do ensino básico (crianças de 6 a 10 anos). A sua constituição deriva da agregação de escolas de reduzida 
dimensão (1 ou 2 turmas), nas quais, em geral, os jardins-de-infância estavam separados do $1^{\circ}$ ciclo.

A referência à designação "centro escolar" surge nos normativos portugueses na sequência de todo um processo iniciado com experiências de agregação de escolas e níveis de ensino, a que se seguiu a constituição de agrupamentos de escolas tendo, portanto, na sua base, uma preocupação organizacional e pedagógica. Estas ideias estariam configuradas, respetivamente, na descentralização e dotação de autonomia às escolas de ensino não-superior, assim como na sua configuração de agrupamento de estabelecimentos (agrupamentos de escolas), que reorganizaram a rede escolar; visando contrariar o insucesso escolar atribuído à desarticulação do percurso escolar dos alunos, promovendo, por um lado, a articulação entre os diferentes níveis de ensino e, por outro, a colegialidade.

A figura do centro escolar colheu a sua base primacial no Programa Especial de Reordenamento da Rede de Escolas do $1^{\circ}$ Ciclo do Ensino Básico (CONSELHO NACIONAL DE EDUCAÇÃO, 2011, p. 18186), visando "requalificar os estabelecimentos que acolheriam as crianças das escolas encerradas, dotando-os de bibliotecas, refeitórios e salas de professores, bem como a criação de incentivos à construção de novos centros escolares". Mais tarde, o Despacho Conjunto n. ${ }^{\circ}$ 200/2005, de 7 de março (PORTUGAL, 2005, p. 3454), legisla sobre os centros escolares "pressupondo a racionalização e potenciação dos investimentos pela aposta em centros escolares que integrem ofertas do pré-escolar e dos $10^{\circ}$ e $2 .^{\circ}$ ciclos do ensino básico”. No ponto $1^{1}$ de critérios de elegibilidade para a requalificação, podemos encontrar preocupações de cariz pedagógico: “c) Projetos que se localizem em zonas afetadas por elevados índices de insucesso escolar; d) Projetos que se localizem em zonas carenciadas de oferta de educação pré-escolar" intencionalidade cujos resultados será necessário avaliar.

Segundo o artigo 40. ${ }^{\circ}$ do Decreto-Lei n. ${ }^{\circ}$ 137/2012, de 2 de julho (PORTUGAL, 2012, p. 3359), os centros escolares estão sob a alçada de um coordenador de estabelecimento, cuja autoridade dimana do diretor do agrupamento de escolas, com o qual deve estar em permanente articulação. Entre as suas competências, inscritas no artigo 41. (PORTUGAL, 2012, p. 3359), salienta-se a manutenção da comunicação entre a comunidade escolar e a comunidade educativa, bem como a coordenação das atividades do estabelecimento.

\footnotetext{
1 O termo "colegialidade" surge, em muitos textos como sinónimo de colaboração, por pressupor que a mesma acontece em função de ssa colegialidade - terminologia sinónima que aqui se adota e subscreve, igualmente, na senda dos investigadores citados
} 


\section{A supervisão colaborativa: um caminho para o desenvolvimento profissional e para a assunção das escolas como comunidades aprendentes}

Em Portugal, há vários anos que a temática da supervisão educacional adquiriu proeminência, embora sendo encarada como uma questão controversa pelos docentes devido à sua conotação com a avaliação de desempenho docente para efeitos de progressão na carreira. Este entendimento decorre da publicação de um conjunto de normativos legais traduzindo-se num sentimento, mais do que num conceito. Todavia, após esse período, verificou-se uma grande evolução na forma de entendimento do conceito. Inclusivamente, como explicitaremos mais adiante, na atualidade, nem todos consideram esta terminologia a mais adequada, preferindo, na supervisão entre pares, ou supervisão colaborativa, expressões como superVisão (ALARCÃO; CANHA, 2013), ou Intervisão (MARTINS, 2017), por forma a demarcar mais claramente esta prática em relação a posturas com um carácter mais inspetivo e vertical que corresponderam a uma realidade inicial, de há várias décadas.

Em Portugal, há vários anos se vem evidenciando um novo olhar sobre a supervisão pedagógica: a reflexão dos docentes para os docentes. Autores como Alarcão e Tavares (2003), entre outros, atribuíram-lhe um papel de relevo, mormente no que concerne às práticas geradas pelos próprios professores. Por outras palavras, enfatiza-se uma "supervisão de matriz essencialmente reflexiva, horizontal, colaborativa ou de auto supervisão, inscrita numa tendência de desenvolvimento profissional e colaboração" (GASPAR; SEABRA; NEVES, 2012, p. 31).

Nesta senda, alguns investigadores mencionam um novo conceito que clarifica a posição horizontal, nivelada, desta visão não-superior, não-fiscalizadora, nem administrativa, mas formativa, como referem Alarcão e Canha (2013, p. 33): "o próprio elemento "visão", tão nuclear ao conceito de supervisão, é hoje visto num ângulo muito mais abrangente [...emergindo] a grafia super-Visão (ou superVisão) por pôr em evidência a importância da visão e da formação em que esta assenta". Neste intuito, Martins (2017), convocando alguns investigadores (como VEEN; ZWART; MEIRINK, 2011), com a terminologia de "peer coaching” e Pawlas e Oliva (2007), sob a designação de "peer counselling e orientada para a resolução de problemas", apresenta o termo Intervisão, para esclarecer que a visão é entre os professores (e não superior aos mesmos): "a intervisão assume-se como uma prática de partilha e colaboração de (auto)aprendizagem sustentada entre pares com situações de hierarquia profissional idênticas" (MARTINS, 2017, p. 14). A este propósito, Alarcão e Canha (2013, p. 46) acentuam, como grande diferença, a existência, não de uma relação vertical, mas horizontal, de "equidade". Alarcão e Roldão (2008, p. 19) já a referiam: “as novas tendências supervisivas apontam para uma 
conceção democrática de supervisão", mas, indo mais além, esclareciam o seu papel reflexivo e de desenvolvimento profissional individual e em comunidade "aprendizagem em colaboração, o desenvolvimento de mecanismos de autosupervisão e auto-aprendizagem, a capacidade de gerar, gerir e partilhar o conhecimento, a assunção da escola como comunidade reflexiva e aprendente”. Esta questão, também foi focada por Prates, Aranha e Loureiro (2010, p. 23), que chamaram a atenção para a função motivadora, esclarecedora e dinamizadora de práticas de supervisão formativa e colaborativa, entre pares, assinalando que a supervisão não se restringe necessariamente à regulação de processos de ensino e aprendizagem e pode alargar-se à escola como organização reflexiva. É neste quadro, que se procurará cruzar a relação entre a supervisão colaborativa, ou a Intervisão (MARTINS, 2017), as escolas, as salas de aula, os docentes e a melhoria das suas práticas.

Gonçalves (2005, p. 15) explicita que o desenvolvimento profissional está nas mãos, em primeiro lugar, do próprio docente e releva a importância das práticas de partilha, diálogo e colaboração, considerando essencial que o professor proceda, não só, à “apropriação, utilização e (re)construção do conhecimento pedagógico"; se disponha a um "posicionamento na dinâmica retroalimentadora dos processos de investigação, inovação e formação"; mas esteja igualmente disponível para "promover e disfrutar de cenários de partilha em que auto-observação e a análise da relação educativa se possam constituir como instrumentos de ajuda na interação com os outros colegas".

Este assumido enfoque na colaboração emerge como essencial e urgente, já que diversos investigadores assinalam a predominância generalizada de práticas de individualismo e de isolamento dos docentes mencionando vicissitudes e desvantagens. É o caso de Lima (2002, p. 27), o qual refere que os professores não conhecem as práticas de sala de aula dos seus colegas, porque não dialogam sobre as mesmas: "raramente trocam pontos de vista ou experiências com eles”. Fullan e Hargreaves (2001, p. 9) assinalam que as práticas individualistas dos professores dificultam o desempenho profissional de qualidade e impedem a mudança e a inovação: "o isolamento profissional dos professores limita o seu acesso a novas ideias e melhores soluções, faz com que o stress seja interiorizado e acumulado, implica o não reconhecimento ou elogio do sucesso e permite a existência e continuação da incompetência."

Cohen (1981, p. 165 apud LIMA 2002, p. 41) afirma, nesta mesma linha de pensamento, a importância de contrariar o individualismo e refere que "a colegialidade é o segredo para a criação de um bom estabelecimento de ensino" e que "a essência de um controlo profissional e de um crescimento intelectual contínuo reside no contacto estimulante com pares que desafiam 
constantemente as ideias existentes". Assim, a colaboração poderá contribuir para a "coordenação de trabalho docente nas diferentes salas de aula"; para melhor "lidar com as inovações pedagógicas e organizacionais" e, mesmo, para apoiar novos profissionais, diminuindo “os efeitos negativos da mobilidade do corpo docente" (LITTLE, 1987, apud LIMA, 2002, p. 41). Também Oliveira-Formosinho (2002, p. 219, citando SENGE,1994, p. 12) afirma a mesma conviç̧ão de que o desenvolvimento profissional docente e a mudança nas escolas seriam potenciados pela colegialidade, considerada indispensável. Como tal, "individual change is vital, but not sufficient [...] if we are going to adresss these conditions in any signifficant way, it wil have to be at the level of collective thinking and understanding", o que, numa tradução nossa poderá ser percebido como: a mudança individual é vital, mas não suficiente e, se pretendemos conduzir tais condições a um nível significativo, terá de ser ao nível do pensamento e do entendimento coletivos.

Igualmente nesta perspetiva, Fullan e Hargreaves (2001, p. 83) enfatizam que a colaboração é associável "a normas e a oportunidades de aperfeiçoamento contínuo e de aprendizagem ao longo da carreira”. Assim, a escola colaborativa (HARGREAVES, 2014; LIMA, 2002), constituir-se-á como comunidade aprendente (SENGE, 1990, apud ALARCÃO; CANHA, 2013) com um papel determinante na melhoria da qualidade da escola. A Figura 1 faz uma síntese destas ideias, articulando os diversos conceitos.

Figura 1- Repercussões da colaboração dos docentes na escola como organização aprendente

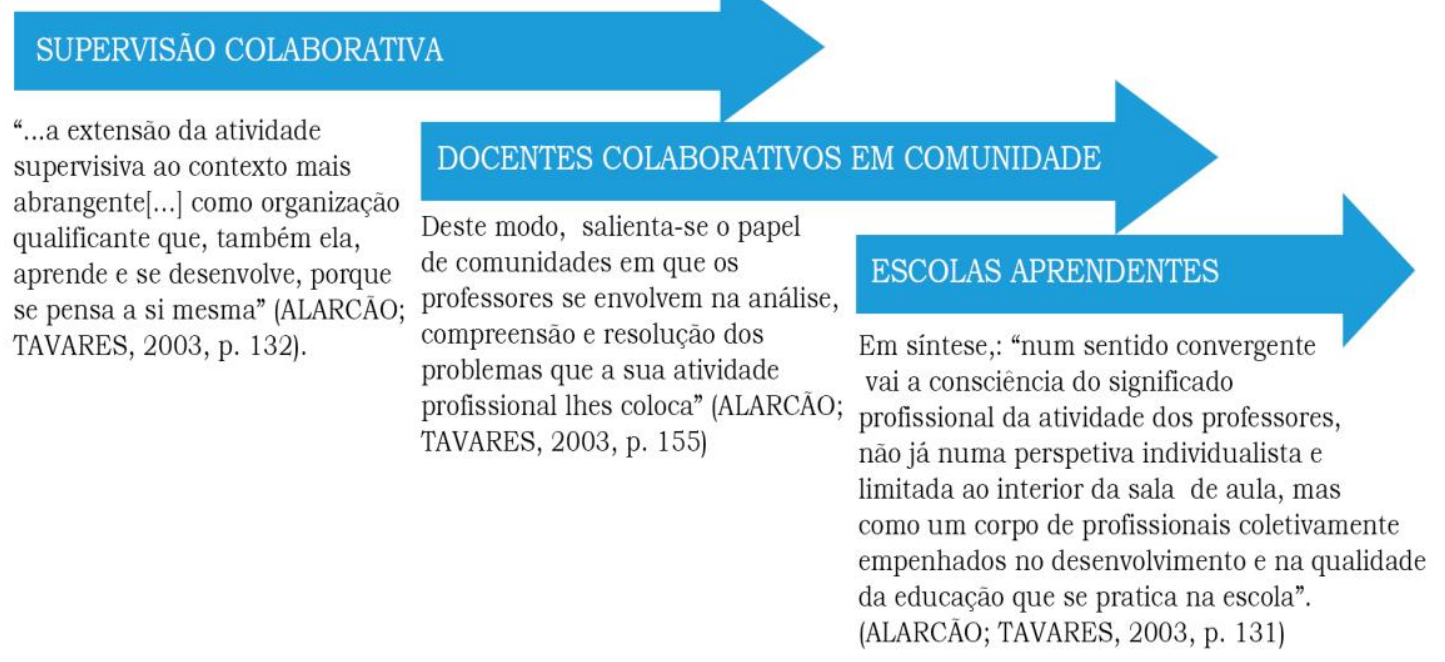

Fonte: criação própria a partir de Alarcão e Tavares (2003) 
Como se percebe a partir do esquema, o fator do envolvimento dos docentes numa comunidade, poderá ser propício à sua colaboração, refletindo-se, por sua vez, no seu desenvolvimento profissional. É precisamente esta a ideia subjacente ao presente estudo: os centros escolares, uma realidade educativa com uma década de existência, poderão ser um alfobre para estas comunidades de aprendizagem?

\section{Práticas colaborativas em centros escolares: metodologia}

Intentando equacionar as práticas colaborativas nos centros escolares como uma eventual supervisão colaborativa propiciadora do crescimento profissional, o estudo, como indica a Figura 2, valeu-se da recolha de dados através da realização de entrevistas semiestruturadas, considerando que, perante uma temática sensível aos profissionais da educação, importaria o diálogo próximo com os docentes, inferindo (ou seja: interpretando) das suas palavras e comportamentos perante as questões, não apenas uma resposta concreta, mas também os sentimentos que a mesma lhes coloca. Justifica-se, desta forma, a opção por uma abordagem próxima do paradigma qualitativo, sob a forma de estudo de caso, cujos princípios metodológicos, de tipo interpretativo, asseguram que "os objetos a estudar não são reduzidos a simples variáveis, são estudados na sua complexidade e inteireza, integrados no seu contexto quotidiano" (FLICK, 2002, p. 5) e, assim, "ricos em fenómenos descritivos relativamente a pessoas, locais e conversas" (BOGDAN; BIKLEN, 1994, p. 16).

Tratando-se de um estudo que implica a participação de pessoas, foram tidas em conta as normas éticas que devem reger a conduta em investigação em ciências sociais, destacando-se o respeito pelo anonimato dos participantes e do contexto estudado, assim como a participação voluntária com base em consentimento informado (AERA COUNCIL, 2011; BAPTISTA (Coord.), 2014). 
Figura 2 - Design metodológico

\begin{tabular}{|l|l|}
\hline Opção metodológica & $\begin{array}{l}\text { Estudo de caso apoiado em entrevistas semi-estruturadas de grupo focal e entrevistas } \\
\text { individuais }\end{array}$ \\
\hline População alvo & $\begin{array}{l}\text { Docentes de educação pré-escolar e do 1. }{ }^{\circ} \text { CEB dos quatro centros escolares de um dado } \\
\text { agrupamento }\end{array}$ \\
\hline $\begin{array}{l}\text { Instrumentos } \\
\text { recolha de dados }\end{array}$ & $\begin{array}{l}\text { Critérios de seleção: } \\
\text {-Grupos focais: docentes que tenham transitado de escolas isoladas (lugar único, ou } \\
\text { reduzida dimensão) para os centros escolares; } \\
\text {-Entrevistas individuais: docentes que, tendo transitado de escolas isoladas, tenham } \\
\text { lecionado mais tempo nas mesmas/ estejam há mais tempo nos centros escolares }\end{array}$ \\
\hline Recolha de dados & $\begin{array}{l}\text { Construção dos guiões apoiada na síntese do enquadramento teórico e do estado da arte } \\
\text { Validação pela consulta de especialistas (acordo entre juízes) }\end{array}$ \\
$\begin{array}{l}\text { Validação pela Direção Geral de Educcăão } \\
\text { - Pedido de autorização aos participantes (consentimento informado) } \\
\text { - Grelha individual de caraterização dos participantes } \\
\text { - Fase 1- quatro entrevistas de grupo focal (realizadas) } \\
\text { - Fase 2- Entrevistas individuais (por realizar) }\end{array}$ \\
\hline Análise de dados & \multicolumn{1}{|c|}{ Análise de conteúdo } \\
\hline
\end{tabular}

Foram, primeiramente, concretizadas as entrevistas de grupo focal que envolveram a participação de 28 docentes que transitaram de escolas isoladas para centros escolares do agrupamento de escolas onde decorre o estudo.

Dos 28 docentes inquiridos, oito pertencem à educação pré-escolar e vinte, ao $1^{\circ}$ ciclo do ensino básico. A grande maioria é do género feminino e integra as cinco décadas de vida. O tempo de serviço situa-se entre os 20 e os 35 anos.

Quase metade dos participantes (onze) exerce uma função relevante no contexto do funcionamento do agrupamento de escolas (AE), diretamente relacionada com a coordenação pedagógica de docentes. A ação de cinco deles tem uma influência predominante no contexto das dinâmicas do centro escolar (CE), como evidencia a Figura 3.

Figura 3- Funções desempenhadas pelos participantes

\begin{tabular}{|l|c|c|}
\hline \multicolumn{1}{|c|}{ Cargo-função } & CE & AE de influência \\
\hline Conselho Geral & & 2 \\
\hline Coordenação de Ciclo & 2 & 1 \\
\hline Coordenador de Estabelecimento & & 3 \\
\hline Coordenação de Ano & 3 & \\
\hline Coordenação de Conselho de Docentes de Avaliação & \\
\hline
\end{tabular}

\section{Resultados}

Nesta fase, salientam-se as tendências de resposta dos professores e educadores participantes no focus group associadas a: 1) mudanças nas práticas docentes; ii) perspetivas sobre supervisão; iii) e individualismo vs. colaboração. 


\subsection{Conjeturar mudanças nas práticas docentes}

Relativamente a este tópico, pretendia-se: i) identificar diferenças e/ou semelhanças nas práticas docentes, antes e depois da transição para os centros escolares; ii) perceber se os docentes associam essa mudança na melhoria das suas práticas, iii) e se identificam fatores envolvidos.

Em síntese, as respostas conduziram às seguintes ideias:

A maior parte dos inquiridos não coloca a tónica das diferenças/semelhanças nas práticas, numa primeira abordagem, mas antes no relacionamento de proximidade com a comunidade educativa, nos espaços...

Numa segunda abordagem, quando a entrevistadora enfatiza o fator "práticas docentes", percebe-se alguma divisão de opiniões: os inquiridos consideram que as suas práticas foram sempre boas e que tinham sido outros fatores a influenciar o ato educativo: C5- "trabalhávamos igual. Melhorou por ter só um nível, mas o empenho é o mesmo". Vários docentes referem ter melhorado, principalmente em função da diversificação e qualidade dos recursos: D1- "no $1^{\circ}$ ciclo (o centro escolar) tem a vantagem de se trabalhar em equipa, por causa dos temas. O nosso trabalho de sala de aula é um bocado solitário e aqui foi uma das grandes diferenças positivas que eu senti"; C6- "a partilha de experiências".

Alguns participantes mencionam práticas inovadoras propiciadas e facilitadas pela coexistência no estabelecimento de docentes: A5-“há muita interação entre as colegas e as crianças das outras salas. Fazem-se muitas atividades em conjunto"; A7- "vemos uma atividade interessante e partilhamos e fazemos juntos"; A3- "fazemos atividades colaborativas".

\subsection{Desocultar perspetivas de supervisão}

Este tópico estava direcionado para identificar conceções e sentimentos sobre supervisão, mormente, colaborativa, tendo sido possível perceber as seguintes ideias:

Os docentes com cargos de coordenação enfatizam uma perspetiva de proximidade aos docentes que coordenam, ou seja, uma supervisão com caráter de ajuda:

Senti-me no papel de supervisora em relação aos meus colegas, senti que assumi esse papel, ao ser coordenadora do estabelecimento, não no intuito de ver se cumpriam, ou não, ou se dão bem as aulas, ou não, mas para saber se estávamos a fazer tudo certo para que depois não nos viessem apontar nada. Não para punir, ou denunciar alguém, mas para saber se está tudo ok. (Entrevistada A1) 
Há uma conotação muito generalizada do termo "supervisão" com sentimentos negativos, como constrangimento, avaliação, controlo. Alguns docentes referiram colaboração, partilha. De notar que estas referências advieram de professores com formação em supervisão.

Quando questionados sobre eventuais práticas de supervisão, no centro escolar, uma grande parte voltou a referir-se à supervisão pela direção, pelos coordenadores, no contexto da avaliação de desempenho docente, ou serviços de inspeção, embora alguns também tenham identificado mais-valias, no vetor colaborativo, para a melhoria das suas práticas docentes. Para grande parte dos inquiridos, a supervisão de avaliação não deveria existir, ou deveria chamar-se super-visão, considerando que as práticas inter-docentes não podem ser acolhidas sob essa terminologia. Não estabelecem, assim, uma conotação do termo com colaboração, embora reconheçam e valorizem a colaboração no centro escolar, no que concerne à articulação, partilha, ajuda, diálogo e melhoria do desempenho: B8- "pela troca de ideias"; B4- "estamos em formação todos os dias. Sozinhos não há formação nenhuma"; B2- "até o conhecimento (aumenta)".

\subsection{Individualismo versus colaboração}

O tópico tinha como intenções desvelar perspetivas, sentimentos e vivências associadas à colaboração/individualismo e identificar indicadores da existência de comunidades de aprendizagem nos centros escolares. Em síntese, as respostas conduziram às seguintes ideias:

As práticas de colaboração são mencionadas pela generalidade dos inquiridos, que entendem que as mesmas são fortemente potenciadas pelos centros escolares. Assinalam, assim a existência de comunidades de aprendizagem nos centros escolares e destacam como essenciais não só as reuniões nos centros, como as interações informais ao longo do dia, incluindo nas viagens de automóvel, também elas favorecidas pela aglomeração dos docentes nos centros escolares.

A existência de um maior número de docentes é referida como um fator propiciador da partilha, embora, por vezes, tenha implicado algum esforço adicional. Assim, a questão da autonomia volta a ser focada, subentendendo que a noção de "minha sala/minha turma/meu trabalho" ainda é sentida como muito importante.

Não obstante, há várias referências ao papel que a mudança para os centros escolares teve ao nível das relações com outros docentes e aos seus reflexos nas práticas de colaboração: B8"há um leque mais abrangente de colegas que podem ajudar, de materiais"; B6- "eu era muito feliz na escola pequena, mas faltava a partilha, porque não havia as reuniões de ano, era só de núcleo". 
Neste ponto do estudo foi, ainda, possível identificar procedimentos de interação interdocentes, averiguando a eventualidade do contributo resultante da agregação dos docentes em centros escolares. Verifica-se alguma dicotomia nas respostas: nalguns casos, é mencionado que o centro escolar propicia partilhas e articulação, mas, noutros, são enfatizadas dificuldades em dialogar. É, pois, necessária uma gestão eficaz das interações, o que implica um esforço dos professores na tomada de decisões, que colide com a sua individualidade. Quanto à questão da articulação, é mencionado que o centro escolar facilita a continuidade educativa entre ambos os níveis - educação pré-escolar e $1^{\circ}$ ciclo do ensino básico: D2- "nas escolas isoladas não era prático, porque estavam separadas (articular pré-escolar e $1^{0}$ ciclo)"; D5- "articulamos em projetos"; D4- "é o bem que o centro trouxe, articulamos mais".

Ao averiguar procedimentos de atualização pedagógica, intentando perceber se algum contributo adveio das trocas interdocentes propiciadas pela coexistência no centro escolar, logramos perceber que, apesar de escassas exceções, surge, efetivamente, como muito visível o papel do centro escolar enquanto recurso privilegiado e de fácil acesso para ultrapassar dificuldades e encontrar estratégias adequadas aos vários desafios com que os docentes se deparam.

Uma diminuta minoria revela preferência por ações de formação e trabalho individualizado como principais fontes de pesquisa, resolução de questões pedagógicas e melhoria da prática docente.

Grande parte dos inquiridos atribui um papel mais importante ao convívio e trabalho nos centros escolares do que a formações institucionalizadas, ou reuniões de outras estruturas. Exceção feita por alguns docentes para as reuniões de grupos de ano: D4- "é a partilha, sobretudo quando somos mais de uma, duas turmas do mesmo ano"; D1- (antes) "o que fazíamos era encontrar outras formas, almoçávamos juntas"; D1- "no $1^{\circ}$ ciclo (o centro escolar) tem a vantagem de se trabalhar em equipa, por causa dos temas. O nosso trabalho de sala de aula é um bocado solitário e aqui foi uma das grandes diferenças positivas que eu senti”; B2- "comentamos as aprendizagens"; B1-“conhecemos bem os alunos uns dos outros e até um bocadinho o que os colegas estão a fazer nas turmas”. A Figura 4 faz uma síntese das respostas sobre esta questão. 
Figura 4 - Procedimentos de atualização pedagógica

A3 - os centros escolares são um ponto positivo, são uma mais-valia, apesar das A7 - a formação e a partilha entre falhas.

A7 - já não me via a trabalhar numa escola pequena sozinha.

B2 - eu tenho algumas dificuldades a nível de informática e no centro escolar há sempre um colega a quem posso pedir ajuda.

B6 - a partilha

B5 - a opinião dos colegas

B4 - as partilhas pedagógicas ajudam muito

B7 - dá-nos certa segurança perante problemas: se achamos que estamos a ser picuinhas e até para mandar mensagens aos pais, é bom poder pedir uma opinião.

C6 - ajuda a atender mais aos alunos, porque podemos conversar mais umas com as outras

C3- desabafar

D2 - nós conversamos muito, não é bem para encontrar estratégias, mas, ao D1- sozinha conversarmos, ao vermos a forma como resolvem as (dificuldades) delas e o facto de haver tanta gente com tantas opiniões.

\section{Considerações finais}

A colaboração é um eixo central do trabalho docente.

Conforme se evidenciou, diversos estudos atribuem um papel determinante na melhoria da qualidade do desempenho às interações entre docentes (PRATES; ARANHA; LOUREIRO, 2010; GASPAR; SEABRA; NEVES, 2012; ALARCÃO; CANHA, 2013; MARCOS; MACHADO; ABELHA, 2014; HARGREAVES, 2014; PEDRAS; SEABRA, 2016). Nas perspetivas destes e de outros investigadores, a partilha de vivências, de modos de fazer, de conceções e de saberes constituiria, de certa forma, uma formação tão, ou mais válida e mais ajustada às necessidades sentidas, em termo de intervenção educativa do que momentos de formação certificados e formais.

Neste artigo, deu-se conta de resultados preliminares de um estudo em curso dedicado a averiguar até que ponto e de que forma a nova realidade dos centros escolares, ao proporcionar a agregação de docentes, terá repercussões nas suas práticas colaborativas e na melhoria do seu desempenho docente.

Quanto à colaboração, as primeiras inferências que se apresentam indiciam que, apesar de múltiplos constrangimentos (extensão do currículo e dimensão das turmas, bem como condicionalismos associados à qualidade dos edifícios onde os centros escolares estão 
implantados), a agregação dos docentes facilitou as atitudes colaborativas e poderá estar a introduzir alguma mudança nas culturas tradicionalmente individualistas que caraterizam a classe docente, sobretudo ao nível do $1^{\circ}$ ciclo do ensino básico, em função da monodocência.

Cogitamos, desta forma, acerca das interações entre professores. Questionamo-nos se o movimentar-se, no centro escolar, de um grupo de profissionais que, permanentemente, observa e escuta ideias, práticas, produtos, constitui, de facto, fonte de aprendizagens colaborativas e origina uma verdadeira comunidade aprendente. A resposta que os dados preliminares do estudo em curso apontam parece ir no sentido afirmativo. Contudo, para aqueles que veem na supervisão uma prática de melhoria de desempenho e apontam a supervisão colaborativa como uma estratégia a incentivar, já a perceção surge mais diversa.

De facto, na realidade portuguesa persiste a conotação pejorativa do termo, associada, ainda, a escrutínio, e não a partilha. Alguns docentes com formação especializada e os agentes de liderança intermédia (coordenadores de estabelecimento e de departamento) que participaram do estudo foram avançando as suas opiniões, contrariando tal entendimento. Todavia, a supervisão, entendida enquanto Intervisão (MARTINS, 2017) ou supervisão entre pares, não pareceu obter corroboração, pelo menos ao nível das respostas obtidas nos grupos focais. A supervisão, em grande parte das respostas dadas pelos docentes, continua a ser conotada com a inspeção ou com a avaliação de desempenho, ficando de fora aquilo que, no nosso entender, tem de maior potencial - o estímulo ao crescimento profissional e pessoal.

Múltiplos outros benefícios poderão tornar-se patentes em resultado destas atitudes colaborativas e da vivência em comunidade, mas as opiniões dos docentes inquiridos levam-nos a refletir e a colocar um conjunto de questões que desejamos ver aprofundas e esclarecidas:

a) Perante a dissociação entre supervisão e colaboração, encaradas pelos inquiridos como polos antitéticos, que fatores poderão estar a impedir de ultrapassar esse entendimento? Será uma questão de falta de esclarecimento, uma vez que as respostas fornecidas em sentido inverso foram avançadas por docentes com formação em supervisão?

b) Quanto às práticas colaborativas, remetendo para respostas que enfatizam a vertente pessoal da empatia entre profissionais enquanto fator relevante na partilha e na colaboração, inquietam-nos as questões do limiar entre os conceitos de colaboração e de intrusão. Com efeito, este último poderá, ou não, estar associado a respostas de docentes de tipo individualista e, consequentemente, dar origem a alguma "fuga" à resposta sobre a hipotética influência dos pares na melhoria das suas práticas. Que atitudes ou que medidas poderão, então, ser tomadas? 
Pensamos que as entrevistas individuais possibilitarão colmatar algumas lacunas nas respostas e contribuir para esclarecer estas questões.

\section{Referências}

AERA Council Code of Ethics. American Educational Research Association. Educational Researcher, v. 40, n. 3, p. 145-156, 2011. Disponível em:

https://journals.sagepub.com/doi/abs/10.3102/0013189X11410403.Acesso em: 19 set. 2019.

ALARCÃO, Isabel. (Org.). Formação reflexiva de professores: estratégias de supervisão. Porto: Porto Editora, 1996.

ALARCÃO, Isabel; CANHA, Bernardo. Supervisão e Colaboração: uma relação para o desenvolvimento. Porto: Porto Editora, 2013.

ALARCÃO, Isabel; ROLDÃO, Maria do Céu. Supervisão: Um contexto de desenvolvimento profissional dos professores. Mangualde: Edições Pedago, 2008.

ALARCÃO, Isabel; TAVARES, José. Supervisão da prática pedagógica: uma perspetiva de desenvolvimento e aprendizagem. Coimbra: Almedina, 2003.

AMARAL, Maria João; MOREIRA, Maria Alfredo; RIBEIRO, Deolinda. O papel do supervisor no desenvolvimento do professor reflexivo: Estratégias de supervisão. In: ALARCÃO, Isabel (Org.), Formação reflexiva de professores: estratégias de supervisão. Porto: Porto Editora, 1996, p. 89122.

BAPTISTA, Isabel. (Coord.). Instrumento para regulação da prática deontológica. Carta ética. Sociedade Portuguesa de Ciências da Educação, 2014. Disponível em:

http://www.spce.org.pt/PDF/CARTAETICA.pdf. Acesso em: 19 set. 2019.

BOGDAN, Robert. e BIKLEN, Sari. Investigação qualitativa em educação. Porto: Porto Editora, 1994.

CAETANO, Ana Paula. Processos participativos e investigativos na mudança dos professores e da escola. Lisboa: Ministério da Educação. Departamento da Educação Básica, 2003.

CONSELHO NACIONAL DE EDUCAÇÃO. Recomendação n. ${ }^{\circ}$ 4/2011. Recomendação sobre reordenamento da rede escolar: a dimensão das escolas e a constituição de agrupamentos. In: Diário da República, 2. ${ }^{a}$ série, n. 80, 26 de Abril de 2011. Disponível em:

http://www.cnedu.pt/content/antigo/images/stories/PDF/Rede_Escolar.pdf $>$ Acesso em: 30 nov.2019.

DAY, Christopher. Desenvolvimento profissional de professores: os desafios da aprendizagem permanente. Porto: Porto Editora, 1999.

FLICK, Uwe. Métodos qualitativos na investigação cientifica). Lisboa: Monitor, 2002. 
FULLAN, Michael e HARGREAVES, Andy. Por que é que vale a pena lutar? O trabalho de equipa na escola. Porto: Porto Editora, 2001.

GASPAR, Maria Ivone; SEABRA, Filipa; NEVES, Cláudia. A supervisão pedagógica:

Significados e operacionalização. Revista Portuguesa de Investigação Educacional, v. 12, p. 27-55, 2012. Disponível em:

https://repositorioaberto.uab.pt/bitstream/10400.2/3632/4/RPIE1202_A_Supervisao_Pedagog ica_Significados_Operacionalizacao.pdf. Acesso em 19 set. 2019.

GASPAR, Maria Ivone et al. Supervisão em contextos de Educação e Formação. Conceções, práticas e possibilidades. Vila Nova de Gaia: Fundação Manuel Leão, 2019.

HARGREAVES, Andy. Professional Capital: Transforming Teaching in Every School, 30 jan. 2014. Disponível em: https://www.youtube.com/watch?v=w7LQhLX2Wek. Acesso em 30 nov 2018.

GONÇALVES, Fernando Ribeiro. A auto-observação e análise da relação educativa: justificação e prática. Porto: Porto Editora, 2005.

IGE. Avaliação Externa das Escolas. Primeiro ciclo de avaliação externa das escolas 2006-2011. Ministério da Educação, 2011. Disponível em:

https://www.igec.mec.pt/content_01.asp?BtreeID=03/01\&treeID=03/01/03/00\&auxID=\&ne wsID $=2492 \#$ content.Acesso em: 30 nov.2018.

IGE Avaliação Externa das Escolas. Terceiro ciclo de avaliação externa das escolas 2018-(...). Ministério da Educação, 2019. Disponível em:

https://www.igec.mec.pt/content_01.asp?BtreeID=03/01\&treeID=03/01/03/00\&auxID=\&ne wsID=2762\#content. Acesso em: 19 set. 2019.

LIMA, Jorge. Ávila. As culturas colaborativas nas escolas: Estruturas, processos e conteúdos. Porto: Porto Editora, 2002.

MARCOS, Ana; ABELHA Marta; Machado, Eusébio André. Effect(s) of Teacher Evaluation on Collaborative Practices: Induction or Inbibition? 2014. Disponível em:

https://www.researchgate.net/publication/277651393 Effects of Teacher Evaluation on Coll aborative Practices Induction or Inhibition. Acesso em 1 nov. 2018.

MARTINS, Dulce. Supervisão pedagógica na educação básica e no ensino secundário, 2016. Disponível em: http://info.ie.uminho.pt/iiiseminarioobservatorio/Workshop_SP/Supervis\%C3\%A30\%20Pedag \%C3\%B3gica EdBasica\&Sec .pdf. Acesso em 30 nov. 2018.

PEDRAS, Sandra; SEABRA, Filipa. Supervisão e Colaboração: contributos para uma relação. Revista Transmutare, Curitiba, v.1, n.2 p. 293-312, jul./dez. 2016. Disponível em: https://periodicos.utfpr.edu.br/rtr/article/view/4379. Acesso em 30 nov.2018.

PORTUGAL. Ministério da Educação; Ministério das Cidades, Administração Local, Habitação e Desenvolvimento Regional. Despacho Conjunto n. ${ }^{\circ}$ 200/2005, de 7 de março. In: Diário da República, 2. ${ }^{a}$ série, n. 46, 7 março 2005. Disponível em: https://dre.tretas.org/pdfs/2005/03/07/dre-182618.pdf. Acesso em 1 nov. 2018. 
PORTUGAL.. Ministério da Educação. Decreto-Lei n. ${ }^{\circ}$ 137/2012, de 2 de julho. In Diário da República, 1. ${ }^{a}$ série, n. 126, 2 julho de 2012. Disponível em:

https://dre.pt/application/conteudo/178527. Acesso em 1 nov. 2018.

PRATES, Maria Lídia; ARANHA, Ágata; LOUREIRO, Armando. Liderança: supervisão e aprendizagem partilhada. EDUSER, v. 2(1), p. 20-36, 2010.

OLIVEIRA-FORMOSINHO, Júlia. (Org.). A supervisão na formação de professores I: Da sala à escola. Porto: Porto Editora, 2002.

Recebido em: 25 set. 2019 / Aprovado em: 21 nov. 2019

\section{$\underline{\text { Cite como }}$}

MIRANDA, Helena Maria Cerqueira Gonçalves; SEABRA, Filipa. Centros escolares e supervisão colaborativa: perspetivas quanto ao contributo para o desenvolvimento profissional e a melhoria das práticas pedagógicas - um estudo em curso. Dialogia, São Paulo, n. 33, p. 143-159, set./dez. 2019. Disponível em: https://doi.org/10.5585/Dialogia.n33.15411. 